\title{
Article
}

\section{Gluten Sensitivity Biomarkers in Menière's Disease: Is It a Gluten Related Disorder?}

\author{
Federica Di Berardino ${ }^{1, *}$, Diego Zanetti ${ }^{1}$, Marina Socci ${ }^{1}$ and Luca Elli ${ }^{2}$
}

1 Audiology Unit, Department of Clinical Science and Community Health, University of Milano, Fondazione IRCCS Cà Granda Ospedale Maggiore Policlinico, Milano, Italy; diego.zanetti.bs@gmail.com (D.Z.);- marina.socci@fastwebnet.it (M.S.)

2 Center for Prevention and Diagnosis of Celiac Disease. Fondazione IRCCS Ca' Granda Ospedale Maggiore Policlinico; lucelli@yahoo.com

* Correspondence: federica.diberardino@unimi.it; Tel.: +39-34-8006-0914.

\begin{abstract}
Background: Meniere's disease (MD) has been recently linked to gluten assumption. Approximately $75 \%$ of MD patients show positive skin test to food and about $50 \%$ of the positive responses are specific to the gliadin acid extract fraction. Aim of this study was to investigate the humoral immune responses to wheat antigens and related autoantigens in MD patients. Methods. We assessed the reactivity of sera from 28 patients with definite MD and 100 healthy controls against a repertoire of 51 antigens usually associated with immune reaction to gluten. Results. MD patients showed an increase of anti-wheat IgA, anti-cerebellar peptide IgA and anti-glutamic acid decarboxylase (GAD) 65 IgM compared to healthy controls. In particular, the increase of antiwheat IgA and GAD 65 IgM has been confirmed in a subgroup of MD patients symptomatically responding to a gluten free diet (GFD). Conclusion. In MD patients, an increase of the antibody production against gluten biomarkers was observed; in particular, anti-wheat IgA seems to be associated to clinical response to GFD.
\end{abstract}

Keywords: gluten; celiac disease; antibodies; Ménière's disease; vertigo

\section{Introduction}

Gluten is the main structural protein in wheat and other cereals (such as barley, rye and spelt); it is insoluble in water and sodium chloride and it can be further subdivided on the basis of the alcohol solubility between gliadins (alcohol soluble) and glutenins. When mixed with water, gluten creates a three-dimensional network, giving dough the typical elasticity and viscosity. [1] The monomeric gliadins comprise the $\omega-, \alpha-$, and $\gamma$-gliadins, based on their mobility on electrophoresis at low $\mathrm{pH}$, while the polymeric types include high molecular weight and low molecular weight subunits of glutenins that are linked by intermolecular disulphide bonds. [2] The interplay between gluten components and the immune system, and its direct cytotoxic effects exerted during the intestinal transit are at the basis of the so-called gluten-related disorders (GRD). [3] GRD is an umbrella term including gastrointestinal, neurological and skin disorders. Following the London classification, GRD are further subdivided on the basis of their etiopathogenesis: autoimmune (celiac disease $[C D]$, gluten ataxia and dermatitis herpetiformis), allergic (wheat allergy) and idiopathic (non celiac gluten sensitivity, NCGS). [3, 4] In particular, NCGS is a syndrome characterized by the onset of gastrointestinal and extraintestinal symptoms after the ingestion of gluten containing food (and the regression after its withdrawal).[5] Although many points about NCGS need to be clarified, it seems frequent in the general population (at least 3\%) and characterized by a clinical picture involving different extraintestinal symptoms included those of neurological and psychiatric origin. [6] On the basis of these findings, different researchers are investigating the presence of biomarkers (antibodies against gluten and its fractions) connecting adverse gluten reaction and patients affected by different disorders of unclear pathogenesis as Meniere's disease (MD). [7] MD is a clinical disorder defined as the idiopathic syndrome of endolymphatic hydrops. [8] Various causes have been ascribed, including trauma, viral infections, metabolic disorders, allergies, and autoimmune factors. 
MD is characterized by intermittent episodes of vertigo lasting from minutes to hours, with fluctuating sensorineural hearing loss, tinnitus, and aural pressure. For the vestibular symptoms, MD is a disabling condition, worsened by the progression of sensorineural hearing loss along the years. Although there is currently no cure, more than $85 \%$ of patients with Meniere's disease are helped by either changes in lifestyle (hyposodic diet, dietary restriction) and medical treatment or minimally invasive surgical procedures such as intratympanic steroid therapy, intratympanic gentamicin therapy, and endolymphatic sac surgery.[9] We focused our study on the humoral immune responses to wheat antigens, particularly on the $\operatorname{IgG}$ and $\operatorname{IgA}$ antibody production against the repertoire of antigens and peptides associated with gliadin in patients with MD.

\section{Materials and Methods}

\section{Patient selection}

$28 \mathrm{MD}$ patients (12 males, mean age $48.6 \pm 7.1$ years) and 16 females (mean age $49.3 \pm 6.8$ years), were enrolled. Following national and international guidelines, $C D$ and wheat allergies were excluded on the basis serological tests (anti tissue transglutaminase IgA/total IgA dosage and sIgE). $[4,10]$ The MD patients were randomly extracted from the 5 years' follow-up group of a previous study from our group.[11] Briefly, the previous study showed that a high percentage of definite MD patients $(82.7 \%)$ were positive to skin prick tests for one or more allergens; in particular, $75.76 \%$ of those who proved to be sensitive to gliadin, had a late-phase gliadin prick test response to the acid fraction of gluten (gliadin/glutentins), which is mainly caused by other immune mediators in any case released by IgE-dependent mast cell degranulation (slow reacting substances such as interleukin 5) rather than histamine (immediately reacting substance).[12]

Among the $28 \mathrm{MD}$ patients, 14 were randomly selected from those reporting a symptomatic response while on a gluten free diet (GFD) [MD/GS+] and 14 from those without response [MD/GS-]. At the time of serological tests all the patients were on a gluten containing diet. Patients with IgA deficiency were excluded from the study.

100 healthy patients, matched for age and sex, (50 males and 50 females, mean age $46.8 \pm 5.3$ years) were used as controls in order to establish the normal range of the tested biomarkers. In healthy controls $\mathrm{CD}$ and wheat allergy were excluded as for MD patients.

\section{Serological antibodies}

An enzyme-linked immunosorbent assay (ELISA) IgG- IgM- and IgA-antibody testing against an array of wheat and associated antigens of both water-soluble and alcohol-soluble proteins was carried out by Cyrex Laboratories (Phoenix, AZ, USA). The antibody panels that were run on every sample included: 1) the amount of IgA and IgG for the peptides (Wheat, Wheat Germ Agglutinin, Alpha Gliadin 33-mer, Alpha Gliadin 17-mer, Gamma Gliadin 15-mer, Omega Gliadin 17-mer, Glutenin 21-mer, Gluteomorphin/Dynorphin, Gliadin/Transglutaminase 2 Complex, Tg2 Tg3, Tg6) and 2) the levels of IgG, IgM, IgA for Myelin Basic Protein, Cerebellar Peptide, Alpha and Beta Tubulin, Myelin Oligodendrocyte Glycoprotein, Ganglioside, Synapsin, Synaptophysin, Glutamic Acid Decarboxylase 65, Synapse Associated Protein). [13]

\section{Statistical analysis}

Levels of significance were calculated using the Statistical Package for the Social Sciences 19.0 for Windows software package (SPSS Inc, Chicago, IL). Owing to the small number of subjects in each group, the Mann-Whitney non parametric test was used to compare groups (MD vs. controls). The antibody levels were expressed as total amount, means \pm SD. Statistical analysis was also performed between age subgroups: MD/GS+ and MD/GS-. Exact Wilcoxon signed-ranks tests (2-tailed) were performed in order to analyse the differences between these two groups. A p_value $<0.05$ was considered statistically significant.

All procedures contributing to this work comply with the ethical standards of the relevant national and institutional guidelines on human experimentation and with the Helsinki Declaration of 1964, as 
revised in 2008. The patients have given signed written consent for publication. The work was carried out in accordance with the Declaration of Helsinki, including, but not limited to there being no potential harm to participants, guaranteed anonymity of participants, and informed consent to their inclusion in the study and to publication. The study was approved by the Internal Ethical Committee.

\section{Results}

The serological profiles of healthy subject and in MD patients are reported in Table 1. A slight general increase of titers against almost all of the analyzed biomarkers was observed. However, the increase was statistically significant for anti-wheat IgA, anti cerebellar peptide IgA and anti-GAD 65 IgM.

In Table 2, a comparison between the serological profiles of MD/GS+ and MD/GS- groups was reported. An increased titer of anti-wheat IgA was confirmed in MD/GS+ compared to MD/GS- (0.7 \pm 0.5 vs $0,4 \pm 0.2, \mathrm{p}=0.034$; healthy subjects value: $0.3 \pm 0.17$ ).

A significant increase of GAD IgM associated with a reduction of GAD IgG was observed in MD/GS+ patients compared to the MD/GS- $(0.79 \pm 0.7$ vs $0.37 \pm 0.3 p=0.049 ; 0.51 \pm 0.31$ vs $0.97 \pm 0.50$, $\mathrm{p}=0.001$, respectively). A reduction of the anti-transglutaminase $3 \operatorname{IgG}(\mathrm{p}=0.001)$, anti-Myelin Basic Protein IgG $(\mathrm{p}=0.039)$ and anti-Myelin Oligodendrocyte Glycoprotein IgG $(\mathrm{p}=0.01)$ was also noted in MD/GS+ patients compared to MD/GS-. These variations occurred within the normal ranges and might have to be considered occasional, in particular when not associated with a concomitant significant modification of the IgM or IgG or IgA titers against the same antigens.

Table 1. Antibodies to the repertoire of wheat antigens in MD and controls

\begin{tabular}{|c|c|c|c|c|c|c|c|}
\hline Biomarker & controls & MD & $\mathbf{p}$ & Biomarkr & controls & MD & p \\
\hline Wheat IgG & $0.9+/-0.3$ & $1.00+/-0.47$ & n.s. & Myelin Basic Protein IgA & $0.56+/-0.23$ & $0.84+/-0.59$ & n.s. \\
\hline Wheat IgA & $0.3+/-0.17$ & $0.72+/-0.51$ & $<0.05$ & Cerebellar Peptide IgG & $0.47+/-0.23$ & $0,63+/-0.27$ & n.s. \\
\hline Wheat Germ Agglutinin IgG & $0.8+/-0.24$ & $0.87+/-0.46$ & n.s. & Cerebellar Peptide IgM & $0.56+/-0.29$ & $0.59+/-0.39$ & n.s. \\
\hline Wheat Germ Agglutinin IgA & $0.35+/-0.21$ & $0.41+/-0.20$ & n.s. & Cerebellar Peptide IgA & $0.48+/-0.24$ & $0,81+/-0.6$ & $<0.05$ \\
\hline Alpha Gliadin 33-mer IgG & $0.6+/-0.28$ & $0.84+/-0.64$ & n.s. & Alpha and Beta Tubulin IgG & $0.7+/-0.32$ & $0.62+/-0.63$ & n.s. \\
\hline Alpha Gliadin 33-mer IgA & $0.2+/-0.14$ & $0.19+/-0.19$ & n.s. & Alpha and Beta Tubulin IgM & $0.51+/-0.23$ & $0.56+/-0.51$ & n.s. \\
\hline Alpha Gliadin 17-mer IgG & $0.3+/-0.15$ & $0.30+/-0.17$ & n.s. & Alpha and Beta Tubulin IA & $0.31+/-0.13$ & $0.41+/-0.23$ & n.s. \\
\hline Alpha Gliadin 17-mer IgA & $0.21+/-0.13$ & $0.22+/-0.28$ & n.s. & $\begin{array}{l}\text { Myelin Oligodendrocyte } \\
\text { Glycoprotein IgG }\end{array}$ & $0.6+/-0.26$ & $0.74+/-0.37$ & n.s. \\
\hline Gamma Gliadin 15-mer IgG & $0.69+/-0.26$ & $0.94+/-0.66$ & n.s. & $\begin{array}{l}\text { Myelin Oligodendrocyte } \\
\text { Glycoprotein IgM }\end{array}$ & $0.53+/-0.24$ & $0.81+/-0.58$ & n.s. \\
\hline Gamma Gliadin 15-mer IgA & $0.22+/-0.13$ & $0.31+/-0.21$ & n.s. & $\begin{array}{l}\text { Myelin Oligodendrocyte } \\
\text { Glycoprotein IgA }\end{array}$ & $0.54+/-0.27$ & $0.77+/-0.34$ & n.s. \\
\hline Omega Gliadin 17-mer IgG & $0.47+/-0.23$ & $0.42+/-0.30$ & n.s. & Ganglioside IgG & $0.38+/-0.25$ & $0.66+/-0.43$ & n.s. \\
\hline Omega Gliadin 17-mer IgA & $0.25+/-0.16$ & $0.35+/-0.28$ & n.s. & Ganglioside IgM & $0.66+/-0.35$ & $0.94+/-0.66$ & n.s. \\
\hline Glutenin 21-mer IgG & $0.9+/-0.33$ & $1,13+/-0.82$ & n.s. & Ganglioside IgA & $0.47+/-0.21$ & $0.66+/-0.38$ & n.s. \\
\hline Glutenin 21-mer IgA & $0.38+/-0.24$ & $0.46+/-0.27$ & n.s. & $\begin{array}{l}\text { Glutamic Acid Decarboxylase } 65 \\
\text { (GAD 65) IgG }\end{array}$ & $0.81+/-0.29$ & $0.58+/-0.36$ & n.s. \\
\hline Gluteomorphin/Dynorphin IgG & $0.43+/-0.19$ & $0.41+/-0.30$ & n.s. & $\begin{array}{l}\text { Glutamic Acid Decarboxylase } \\
65 \text { (GAD 65) IgM }\end{array}$ & $0.41+/-0.18$ & $0.74+/-0.68$ & $<0.05$ \\
\hline Gluteomorphin/Dynorphin IgA & $0.21+/-0.11$ & $0.22+/-0.16$ & n.s. & $\begin{array}{l}\text { Glutamic Acid Decarboxylase } 65 \\
\text { (GAD 65) IgA }\end{array}$ & $0.5+/-0.17$ & $0.49+/-0.18$ & n.s. \\
\hline $\begin{array}{l}\text { Gliadin/Transglutaminase } 2 \\
\text { Complex IgG }\end{array}$ & $0.51+/-0.23$ & $0.60+/-0.46$ & n.s. & Synapsin IgG & $0.17+/-0.13$ & $0.23+/-0.31$ & n.s. \\
\hline $\begin{array}{l}\text { Gliadin/Transglutaminase } 2 \\
\text { Complex IgA }\end{array}$ & $0.15+/-0.9$ & $0.23+/-0.17$ & n.s. & Synapsin IgM & $0.38+/-0.17$ & $0.62+/-0.59$ & n.s. \\
\hline Transglutaminase 2 IgG & $1.1+/-4.3$ & $1.15+/-0,51$ & n.s. & Synapsin IgA & $0.17+/-0.12$ & $0.24+/-0.20$ & n.s. \\
\hline Transglutaminase 2 IgA & $0.4+/-0.24$ & $0,70+/-0.41$ & n.s. & Synaptophysin IgG & $0.54+/-0.21$ & $0.55+/-0.48$ & n.s. \\
\hline Transglutaminase 3 IgG & $0.52+/-0.27$ & $0.55+/-0.27$ & n.s. & Synaptophysin IgM & $0.48+/-0.19$ & $0.60+/-0.53$ & n.s. \\
\hline Transglutaminase 3 IgA & $0.23+/-0.18$ & $0.33+/-0.20$ & n.s. & Synaptophysin IgA & $0.32+/-0.17$ & $0.37+/-0.23$ & n.s. \\
\hline Transglutaminase 6 IgG & $0.43+/-0.22$ & $0.49+/-0.30$ & n.s. & Synapse Associated Protein IgG & $0.42+/-0.18$ & $0.55+/-0.42$ & n.s. \\
\hline Transglutaminase $6 \operatorname{Ig} \mathrm{A}$ & $0.21+/-0.15$ & $0.25+/-0.12$ & n.s. & Synapse Associated Protein IgM & $0.47+/-0.21$ & $0.88+/-0.69$ & n.s. \\
\hline Myelin Basic Protein IgG & $0.6+/-0.21$ & $0.71+/-0.31$ & n.s. & Synapse Associated Protein IgA & $0.3+/-0.17$ & $0.28+/-0.15$ & n.s. \\
\hline Myelin Basic Protein IgM & $0.54+/-0.19$ & $0.69+/-0.35$ & n.s. & & & & \\
\hline
\end{tabular}


Table 2. Gluten biomarkers in MD-GS+ and MD-GS- subjects

\begin{tabular}{|c|c|c|c|c|c|}
\hline Biomarker & controls & MD & MD-GS- & MD-GS+ & p \\
\hline Wheat IgG & $0.9+/-0.3$ & $1.00+/-0.47$ & $1.0+/-0.50$ & $1.1+/-0.50$ & n.s. \\
\hline${ }^{*}$ Wheat IgA & $0.3+/-0.17$ & $0.72+/-0.51$ & $0.41+/-0.21$ & $0.74+/-0.50$ & 0.034 \\
\hline Transglutaminase 3 IgG & $0.52+/-0.27$ & $0.55+/-0.27$ & $0.86+/-0.38$ & $0.52+/-0.24$ & 0.001 \\
\hline Transglutaminase 3 IgA & $0.23+/-0.18$ & $0.33+/-0.20$ & $0.36+/-0.25$ & $0.33+/-0.20$ & n.s. \\
\hline Cerebellar Peptide IgM & $0.56+/-0.29$ & $0.59+/-0.39$ & $0.51+/-0.28$ & $0.83+/-0.60$ & n.s. \\
\hline${ }^{*}$ Cerebellar Peptide IgA & $0.48+/-0.24$ & $0,81+/-0.6$ & $0.52+/-0.22$ & $0.60+/-0.40$ & n.s. \\
\hline Myelin Basic Protein IgG & $0.6+/-0.21$ & $0.71+/-0.31$ & $0.90+/-0.27$ & $0.69+/-0.31$ & 0.039 \\
\hline $\begin{array}{l}\text { Myelin Oligodendrocyte } \\
\text { Glycoprotein IgG }\end{array}$ & $0.6+/-0.26$ & $0.74+/-0.37$ & $1.04+/-0.44$ & $0.71+/-0.35$ & 0.013 \\
\hline $\begin{array}{l}\text { Myelin Oligodendrocyte } \\
\text { Glycoprotein IgM }\end{array}$ & $0.53+/-0.24$ & $0.81+/-0.58$ & $0.86+/-0.79$ & $0.83+/-0.58$ & n.s. \\
\hline $\begin{array}{l}\text { Myelin Oligodendrocyte } \\
\text { Glycoprotein IgA }\end{array}$ & $0.54+/-0.27$ & $0.77+/-0.34$ & $0.79+/-0.38$ & $0.77+/-0.35$ & n.s. \\
\hline $\begin{array}{c}\text { Glutamic Acid Decarboxylase } 65 \\
\text { (GAD 65) IgG }\end{array}$ & $0.81+/-0.29$ & $0.58+/-0.36$ & $0.97+/-0.50$ & $0.51+/-0.32$ & 0.001 \\
\hline $\begin{array}{c}\text { * Glutamic Acid Decarboxylase } 65 \\
\text { (GAD 65) IgM }\end{array}$ & $0.41+/-0.18$ & $0.74+/-0.68$ & $0.37+/-0.31$ & $0.79+/-0.72$ & 0.049 \\
\hline $\begin{array}{c}\text { Glutamic Acid Decarboxylase } 65 \\
\text { (GAD 65) IgA }\end{array}$ & $0.50+/-0.17$ & $0.49+/-0.18$ & $0.43+/-0.13$ & $0.51+/-0.21$ & n.s. \\
\hline
\end{tabular}

* the difference between MD and controls was statistically significant.

\section{Discussion}

Our study demonstrated a different serological profiles between MD patients responding and not responding to a GFD, with the concomitant presence of an immunological reaction against gluten and and autoimmune antigens of the nervous system.

Many authors are studying the characterization of the whole repertoire of wheat antigens involved in the humoral immune responses in patients with diseases that are related to the wheat ingestion, in order to define the possible overlap of GS with other inflammatory bowel diseases and extraintestinal disorders targeting the nervous system. $[13,14]$ In such cases, the innate or adaptive immune response (humoral or cellular) to gluten/wheat results in the presentation of three distinct conditions that are triggered by the ingestion of wheat protein: $C D$, wheat allergy, and NCGS. [15, 16] A possible relationship between NCGS and MD has been previously suggested. [17, 18]

Early studies categorized wheat proteins into four groups according to solubility: water-soluble albumins, salt-soluble globulins, ethanol-soluble gliadins, and alkaline/acid-soluble glutenins, [19] but the proteomic map of wheat identified $~ 1000$ individual antigens. [20] For this specific reason, we planned to check the serological profile, in search of a possible useful biomarker to assist in diagnosing gluten immune reactivity and sensitivity.

Anti wheat IgA, that resulted increased in MD group compared to the controls, is an expression of the increased mucosal response to a polyantigenic (Triticum aestivum) extract containg gliadin and gluten and other peptides in the MD subject. Anti wheat IgA increase was confirmed in the MD/GS+ group (GFD responsive) compared to the MD/GS- group (GFD unresponsive). This finding supports 
the assumption of a relation between wheat/gluten containing diet and MD in a number of patients. Moreover, it should be stressed that IgA have a mucosal origin and thus could be directly produced by small bowel being involved in a gut-brain immunological axis. [21] However, anti-wheat IgA are found in high percentage of normal blood donors [21] and in 33\% of asthma bakery subjects, [22] therefore they might be considered with caution.

Differently from what observed in the "classical" gluten-related autoimmune pathway, in our study transglutaminases seem not involved as autoaintigen. In fact, transglutaminase enzymatic family is usually targeted in the GRD with an autoimmune pathomechanism: transglutaminase type 2 in CD, transglutaminase type 6 in neurological diseases and type 3 in dermatitis herpetiformis. [4] In our cohort of MD patients, we did not note any signature of anti transglutaminase reaction.

While the increase anti-cerebellar peptide IgA was an isolated finding, a significant increase of GAD IgM associated with a reduction of GAD IgG was observed in MD patients and confirmed in MD/GS+ patients compared to the MD/GS-. Anti-GAD antibodies are particularly common in autoimmune diseases, such as thyroid disease and rheumatoid arthritis. There are two isoenzyme of GAD, with molecular weights of 67 and $65 \mathrm{kDa}$, respectively. [23]

In literature, higher title of $\mathrm{Ab}$ anti GAD 65 (>1.53) are used in the differential diagnosis between a late onset of type 1 mellitus diabetis and type 2 diabetes [23] and Ab anti GAD 67 have been associated with a disease characterized by stiffness of the muscles, acute vestibular damage and cerebellar ataxia. [24] In that report, the authors concluded that a peripheral vertigo is possibly related to a lack of gamma aminobutyric acid. No other reports on acute vestibular damage with a possible correlation with anti-glutamic acid decarboxylase antibodies has been described. The finding of an increased of anti GAD $65 \mathrm{IgM}$ in the MD group supports the hypothesis that an increase of anti GAD antibodies underlines the possible role of gamma aminobutyric acid as a neurotransmitter in the peripheral vestibular system, reported by Teggi et al. [24] Furthermore, it is well known that the incidence of autoimmune disease and thyroiditis is increased in MD. [8]

Our data confirm the ethiopathogenetic role of immune response in MD, in agreement with other recent observations. $[25,26,27]$ and our previous observation of a gluten immune reactivity in MD patients. [17, 18]

The association between NCGS and MD should be supported by dietary exclusions and challenges: symptoms improve or disappear upon gluten withdrawal, while they recur if gluten is reintroduced in the diet. $[28,29,30]$ However, withdrawal diets and subsequent challenge tests, that are frequently declined by patients, owing to the consistent side effects. Therefore, further studies are also needed to define the clinical relevance of other biomarkers.

Acknowledgments: The Authors are grateful to Dr. O'Bryan and to the Cyrex Laboratories for the serological analysis and to Dr Luigi Di Berardino for his immunological expertice. No funding source was secured for this study.The authors report no financial interest in the subject matter, no actual/potential conflict of interest. Authors have no relationship with commercial companies.

Author Contributions: This paper has not been published elsewhere and has not been submitted simultaneously for publication elsewhere. FDB conceived and designed the study, has followed directly the patients, wrote the paper. DZ analyzed data, wrote, supervised and reviewed the article. MS performed patients' selection and the experiments' data collection. LE gave his technical and specialist support; analyzed data; reviewed the article.

Conflicts of Interest: The authors declare no conflict of interest.

\section{References}

1. Volta U, De Giorgio R. New understanding of gluten sensitivity. Nat Rev Gastroenterol Hepatol 2012; 9: 295-299.

2. Barak S, Mudgil D, Khatkar BS. Biochemical and functional properties of wheat gliadins: a review. Crit Rev Food Sci Nutr. 2015; 55(3): 357-68.

3. Sapone A, Bai JC, Ciacci C, Dolinsek J, Green PH, Hadjivassiliou M, Kaukinen K, Rostami K, Sanders DS, Schumann M, Ullrich R, Villalta D, Volta U, Catassi C, Fasano A. Spectrum of gluten-related disorders: consensus on new nomenclature and classification. BMC Med. 2012; 7;10:13.

4. Elli L, Villalta D, Roncoroni L, Barisani D, Ferrero S, Pellegrini N, Bardella MT, Valiante F, Tomba C, Carroccio A, Bellini M, Soncini M, Cannizzaro R, Leandro G. Nomenclature and diagnosis of gluten-related 
disorders: A position statement by the Italian Association of Hospital Gastroenterologists and Endoscopists (AIGO). [published online November 2016] Dig Liver Dis. pii: S1590-8658(16)30782-4. doi:10.1016/j.dld.2016.10.016.

5. Catassi C, Bai JC, Bonaz B, Bouma G, Calabrò A, Carroccio A, Castillejo G, Ciacci C, Cristofori F, Dolinsek J, Francavilla R, Elli L, Green P, Holtmeier W, Koehler P, Koletzko S, Meinhold C, Sanders D, Schumann M, Schuppan D, Ullrich R, Vécsei A, Volta U, Zevallos V, Sapone A, Fasano A. Non-Celiac Gluten sensitivity: the new frontier of gluten related disorders. Nutrients 2013; 26;5(10):3839-53.

6. Volta U, Bardella MT, Calabrò A, Troncone R, Corazza GR; Study Group for Non-Celiac Gluten Sensitivity. An Italian prospective multicenter survey on patients suspected of having non-celiac gluten sensitivity. BMC Med. 2014; 23; 12-85.

7. Hadjivassiliou M, Rao DG, Grìnewald RA, Aeschlimann DP, Sarrigiannis PG, Hoggard N, Aeschlimann P, Mooney PD, Sanders DS. Neurological Dysfunction in Coeliac Disease and Non-Coeliac Gluten Sensitivity. Am J Gastroenterol. 2016; 111(4): 561-7.

8. Lopez-Lopez-Escamez JA, Carey J, Chung WH, Goebel JA, Magnusson M, Mandalà M, Newman-Toker DE, Strupp M, Suzuki M, Trabalzini F, Bisdorff A. Classification Committee of the Barany Society; Japan Society for Equilibrium Research; European Academy of Otology and Neurotology (EAONO); Equilibrium Committee of the American Academy of Otolaryngology-Head and Neck Surgery (AAO-HNS); Korean Balance Society. Diagnostic criteria for Menière's disease. J Vestib Res. 2015; 25(1):1-7.

9. Sajjadi H, Paparella MM. Meniere's disease. Lancet. 2008; 2;372(9636):406-14.

10. Ludvigsson JF, Bai JC, Biagi F, Card TR, Ciacci C, Ciclitira PJ, Green PH, Hadjivassiliou M, Holdoway A, van Heel DA, Kaukinen K, Leffler DA, Leonard JN, Lundin KE, McGough N, Davidson M, Murray JA, Swift GL, Walker MM, Zingone F, Sanders DS. BSG Coeliac Disease Guidelines Development Group. British Society of Gastroenterology. Diagnosis and management of adult coeliac disease: guidelines from the British Society of Gastroenterology. Gut 2014; 63(8):1210-28.

11. Di Berardino F, Cesarani A. Gluten sensitivity in Meniere's disease. Laryngoscope 2012; 122(3):700-2.

12. Errigo E. Malattie allergiche. Rome, Italy: Lombardo Editore 1999; 1:116.

13. Vojdani A. The characterization of the repertoire of wheat antigens and peptides involved in the humoral immune responses in patients with gluten sensitivity and Crohn's disease. Allergy 2011; 27; 2011:950104.

14. Infantino M, Manfredi M, Meacci F, Grossi V, Severino M, Benucci M, Bellio E, Bellio V, Nucci A, Zolfanelli F, Ugolini S, Catani S, Macchia D. Diagnostic accuracy of anti-gliadin antibodies in Non Celiac Gluten Sensitivity (NCGS) patients: A dual statistical approach. Clin Chim Acta 2015; 7;451(Pt B):135-41.

15. Catassi C, Fasano A. Celiac disease. Curr Opin Gastroenterol 2008; 24: 687-691.

16. Anderson LA, McMillan SA, Watson RG, Monaghan P, Gavin AT, Fox C, Murray LJ. Malignancy and mortality in a population-based cohort of patients with coeliac disease or gluten sensitivity. World J Gastroenterol 2007; 13: 146-151.

17. Di Berardino F, Cesarani A. Gluten sensitivity in Meniere's disease. Laryngoscope 2012; 122(3):700-2.

18. Di Berardino F, Filipponi E, Alpini D, O'Bryan T, Soi D, Cesarani A. Ménière disease and gluten sensitivity: recovery after a gluten-free diet. Am J Otolaryngol. 2013; 34(4):355-6.

19. Osborne TB. The proteins of the wheat kernel. Washington: Carnegie Institution of Washington publication. 1907. DOI: 10.1126/science.26.677.865

20. Tatham AS., Hayes L., Shewry PR, Urry DW. Wheat seed exhibit a complex mechanism of protein elasticity. Biochem Biophys Acta 2001; 1548(2): 187-93

21. Vojdani A, Kharrazian D, Mukherjee PS. The prevalence of antibodies against wheat and milk proteins in blood donors and their contribution to neuroimmune reactivities. Nutrients 2013; 19;6(1):15-36.

22. Bittner C, Grassan B, Frenzel K, Baur X. Identification of wheat gliadins as an allergen family related to baker's asthma. J Allergy Clin Immunol. 2008; 121:744-9.

23. Erlander MG, Tillakaratne NJ, Feldblum S, Patel N, Tobin AJ. Two genes encode distinct glutamate decarboxylases". Neuron 1991; 7 (1): 91-100.

24. Teggi R, Piccioni LO, Martino G, Bellini C, Bussi M. Stiff-person syndrome with acute recurrent peripheral vertigo: possible evidence of gamma aminobutyric acid as a neurotransmitter in the vestibular periphery. J Laryngol Otol. 2008; 122(6):636-8.

25. Elli L, Tomba C, Branchi F, Roncoroni L, Lombardo V, Bardella MT, Ferretti F, Conte D, Valiante F, Fini L, Forti E, Cannizzaro R, Maiero S, Londoni C, Lauri A,Fornaciari G, Lenoci N, Spagnuolo R, Basilisco G, Somalvico F, Borgatta B, Leandro G, Segato S, Barisani D, Morreale G, Buscarini E. Evidence for the Presence of Non-Celiac Gluten Sensitivity in Patients with Functional Gastrointestinal Symptoms: Results from a Multicenter Randomized Double-Blind Placebo-Controlled Gluten Challenge. Nutrients 2016; 8;8(2):84.

26. Brusca I. Overview of biomarkers for diagnosis and monitoring of celiac disease. Adv Clin Chem. 2015; 68:1-55. 
27. Lebwohl B, Ludvigsson JF, Green PH. Celiac disease and non-celiac glutensensitivity. BMJ 2015; 5;351:h4347.

28. Mansueto P, Seidita A, D'Alcamo A, Carroccio A. Non-celiac gluten sensitivity: literature review. J Am Coll Nutr. 2014; 33(1):39-54.

29. Collyer EM, Kaplan BS. Nonceliac gluten sensitivity: an approach to diagnosis and management. Curr Opin Pediatr. 2016; 28(5):638-43.

30. Molina-Infante J, Carroccio A. Suspected Non-celiac Gluten Sensitivity Confirmed in few Patients After Gluten Challenge in Double-blind, Placebo-controlled Trials. [published online August 2016] Clin Gastroenterol Hepatol. pii: S1542-3565(16)30547-X. doi: 10.1016/j.cgh.2016.08.007. 